\title{
Organically Managed Soils Reduce Internal Colonization of Tomato Plants by Salmonella enterica Serovar Typhimurium
}

\author{
Ganyu Gu, Juan M. Cevallos-Cevallos, Gary E. Vallad, and Ariena H. C. van Bruggen
}

First, second, and fourth authors: Emerging Pathogens Institute and Department of Plant Pathology, University of Florida, Gainesville 32611; and third author: Gulf Coast Research and Education Center, University of Florida, Wimauma 33598. Accepted for publication 28 December 2012.

\section{ABSTRACT}

Gu, G., Cevallos-Cevallos, J. M., Vallad, G. E., and van Bruggen, A. H. C. 2013. Organically managed soils reduce internal colonization of tomato plants by Salmonella enterica serovar Typhimurium. Phytopathology 103:381-388.

A two-phase experiment was conducted twice to investigate the effects of soil management on movement of Salmonella enterica Typhimurium in tomato plants. In the first phase, individual leaflets of 84 tomato plants grown in conventional or organic soils were dip inoculated two to four times before fruiting with either of two Salmonella Typhimurium strains $\left(10^{9} \mathrm{CFU} / \mathrm{ml} ; 0.025 \%\right.$ [vol/vol] Silwet L-77). Inoculated and adjacent leaflets were tested for Salmonella spp. densities for 30 days after each inoculation. Endophytic bacterial communities were characterized by polymerase chain reaction denaturing gradient gel electrophoresis before

Fresh fruit and vegetables are increasingly recognized as vehicles for transmission of human enteric pathogens $(4,9,18)$. Consumption of Salmonella-contaminated produce, such as tomato, has led to several multistate and international salmonellosis outbreaks in recent years $(13,14,23,27)$.

Contamination of produce may occur in production fields as well as during processing $(19,32)$. Contaminated animal excrements, protozoa, snails, irrigation water, rain splash, and soil as well as insufficiently composted manure have been identified as potential sources of Salmonella contamination of plants in the field $(6,11,15,35,53)$. Seed have not been investigated as a potential source of Salmonella spp. in the field, although the American Seed Trade Association declared that seed are not contaminated (http://www.amseed.com/news_FoodSafety.asp).

In addition to contamination of sprouts (51), leaves (12), and fruit $(26,44)$, Salmonella enterica can colonize seed $(41,61)$ of a variety of plant species. The interaction with various plant tissues depends on the particular bacterial serovar, plant cultivar, and age $(5,7,8,10,36,39,49)$. In addition to surface contamination, internalization of Salmonella spp. in plants, especially in lettuce and tomato plants, has been reported $(24,26,38)$. S. enterica Typhimurium can reach tomato fruit via internal translocation from leaves probably through phloem (24). The chance of internal movement is low but, once Salmonella cells reach a fruit, they can multiply to high densities within that fruit $(24,49)$.

Because organic plant production mainly relies on soil amendments with composted manure or garden waste to maintain soil

Corresponding authors: G. Gu; E-mail address: ggu@ufl.edu

A. H. C. van Bruggen; E-mail address: ahcvanbruggen@ufl.edu

http://dx.doi.org/10.1094/PHYTO-04-12-0072-FI

(C) 2013 The American Phytopathological Society and after inoculation. Fruit and seed were examined for Salmonella spp. incidence. In phase 2, extracted seed were planted in conventional soil, and contamination of leaves and fruit of the second generation was checked. More Salmonella spp. survived in inoculated leaves on plants grown in conventional than in organic soil. The soil management effect on Salmonella spp. survival was confirmed for tomato plants grown in two additional pairs of soils. Endophytic bacterial diversities of tomato plants grown in conventional soils were significantly lower than those in organic soils. All contaminated fruit $(1 \%)$ were from tomato plants grown in conventional soil. Approximately 5\% of the seed from infested fruit were internally contaminated. No Salmonella sp. was detected in plants grown from contaminated seed.

Additional keywords: endophytic bacterial community, seed contamination.

fertility, it has been suggested that the risk of contamination with enteric pathogens may be higher on organic than on conventional produce (45). However, this has not been proven. Although the prevalence of generic Escherichia coli was higher in noncertified organic produce, it was similar in certified organic compared with conventional produce (45). E. coli O157:H7 was not detected in any produce samples, and a Salmonella $\mathrm{sp}$. was isolated only once from produce from an uncertified small farm (45). A similar study was conducted to compare organic and conventional produce directly from the field; no samples were positive for either $E$. coli O157:H7 or Salmonella spp. (46). Because chicken manure is frequently used to produce organic vegetables, it is relevant to mention that the prevalence of Salmonella spp. is commonly lower in certified-organic chickens than in conventionally raised birds (2), so that the risk of Salmonella spp. can be reduced by using manure from organically produced chickens.

Despite the use of composted manure at organic farms (in particular, chicken manure), it is difficult to predict whether Salmonella spp. could colonize organically grown plants more readily than conventionally grown plants. The absence of synthetic pesticides combined with the application of organic materials generally results in a higher stable organic matter content; greater porosity and water-holding capacity; greater microbial and faunal biomass, activity, and diversity; and reduced availability of soluble nitrogen in organic compared with conventional soils $(34,56)$. These changes in soil quality affect plant physiology $(21)$ and, possibly, the resistance to colonization by microorganisms, including plant and human pathogens (34). Additionally, plants can exploit microbial consortia from soil to protect themselves against infection $(22,30,31,42)$. Previous studies indicated that the population density and diversity of nonpathogenic microbial communities were higher in organic lettuce and edible flowers than those in conventional ones $(50,60)$. There are also indications that there is a negative correlation between enteropathogen 
populations and microbial diversity in manure, soil, and plants $(18,36,58,59)$.

In this study, we investigated the internal colonization and seed transmission of $S$. enterica Typhimurium in tomato plants, and evaluated the effect of soil management type on endophytic bacterial communities, internal persistence and translocation of Salmonella spp. in the plants.

\section{MATERIALS AND METHODS}

Bacterial strains and plant preparation. S. enterica Typhimurium strains MAE110 and MAE119 carrying kanamycin resistance and green fluorescent protein (GFP) genes on the chromosome were provided by Dr. Ute Römling (63). Bacterial cultures were stored in Luria-Bertani (LB) broth containing $25 \%$ glycerol at $-80^{\circ} \mathrm{C}$. For each experiment, a loopful of the stored culture was added to shake cultures $(150 \mathrm{rpm}$ ) of LB broth (kanamycin at $50 \mu \mathrm{g} / \mathrm{ml}$ ) and grown for 18 to $20 \mathrm{~h}$ at $37^{\circ} \mathrm{C}(54)$. The culture was harvested by centrifugation. The pellets were suspended in sterile distilled water (SDW) to a concentration of $10^{9} \mathrm{CFU} / \mathrm{ml}$.

Tomato seed (Solanum lycopersicum 'Florida Lanai'), which were kindly provided by Dr. Jane Polston, were surface disinfected with $1 \mathrm{M} \mathrm{HCl}$ for $30 \mathrm{~min}$ and germinated in potting mix. At 2 weeks post-seeding, seedlings were transplanted to sandy loam soils in $15-\mathrm{cm}$-diameter pots placed on saucers to prevent water leaching. Water was applied at a 2-day interval in the saucers so that water moved upward in the soil. Fertilization was applied weekly on the soil surface with $8 \mathrm{~g}$ of Black Kow (N-P-K = 0.5:0.5:0.5; composted cow manure; Black Gold Compost Co., Oxford, FL) for organic soil and $150 \mathrm{ml}$ of half-strength Hoagland solution ( $\mathrm{pH} \mathrm{6.8)} \mathrm{for} \mathrm{conventional} \mathrm{soil,} \mathrm{which} \mathrm{supplied}$ similar amounts of nitrogen and did not drain into the saucer. Plants were grown in a biological safety level-2 greenhouse equipped with ridge vents, a cooling air-conditioning unit, and a gas heater. The temperature fluctuated between 23 and $33^{\circ} \mathrm{C}$, with an average temperature of $28^{\circ} \mathrm{C}$. Other than natural daylight, no additional lighting was provided.

Experimental setup. A two-phase main experiment was conducted twice (experiment 1 in 2009 and experiment 2 in 2010) to investigate soil management effects on Salmonella spp. survival inside tomato plants and the possibility of seed transmission. In the first phase of experiments 1 and 2, 126 tomato plants were evenly divided over seven blocks located on three greenhouse benches. In each block, nine plants were grown in conventional soil and the other nine in organic soil, six of the nine plants were randomly inoculated with GFP-labeled $S$. enterica Typhimurium strain MAE110 or strain MAE119, and the other three plants were dipped in SDW (three plants per treatment per block). Each year, 84 tomato plants grown in conventional (42 plants) or organic (42 plants) soils were inoculated two to four times before fruiting with $S$. enterica Typhimurium strains, and 42 plants grown in the same conventional or organic soils were treated with SDW as control (Table 1). There were no significant interactions between bacterial strains and soil management types for the internal survival of Salmonella spp. in inoculated tomato leaves and colonization of fruit; therefore, main effects of morphotype and soil management were analyzed separately. Previously, we reported the effect of morphotype of bacterial strains on the internal survival of Salmonella spp. in tomato leaves regardless of the soil management type (24). In this article, we focus on effects of soil management type, while the data of Salmonella strains MAE110 and MAE119 are lumped. In the second phase of experiments 1 and 2, seed extracted from both contaminated and noncontaminated fruit obtained in the first generation were sown in the potting mix with one-third peat and two-thirds sand (experiment 1, with 135 seeds) or conventional soil (experiment 2, with 130 seeds) to detect the possible contamination of the second generation plants. A completely random design was used to detect seed transmission of Salmonella spp. at this stage.

One extra experiment (experiment 3 in 2011) was conducted to confirm the soil management effect on the internal survival of Salmonella spp. in tomato leaves. In total, 16 tomato seedlings were planted randomly in two pairs of conventional and organic soils and inoculated with Salmonella strain MAE110 (4 plants per treatment). The same numbers of plants were treated with SDW as control.

Soil collection and analysis. For experiment 1 in 2009, conventional and organic sandy loam soils were collected from intensively managed research plots at the Plant Science Experiment Station of the University of Florida (Citra) and Rose's Organic Farm (Gainesville, FL), respectively. The same conventional and organic soils were collected from the same plots for experiment 2 . In the Citra conventional farm (C1), potato and corn had been planted in 2009, peanut and triticale in 2010, and soybean in 2011. At Rose's organic farm (O1), Brassicaceae, including broccoli, cauliflower, kale, and radish, and Chenopodiaceae such as spinach, Swiss chard, and beet, had been grown in winter in all years. In the spring, Cucurbitaceae, including cucumber and squash, along with Solanaceae, including tomato, eggplant, and pepper, had been planted.

In experiment 3 , two additional pairs of conventional and organic sandy loam soils were collected from different plots in the Plant Science Experiment Station of the University of Florida at Citra (C2 and O2) and from two adjacent farms in Bell, FL (C3 and O3). At C2, okra had been planted in 2009, snap bean and bahia grass in 2010, and watermelon in 2011. At O2, winter rye and cucumber had been grown in 2009, sun hemp in 2010, and tomato and squash in 2011. Peanut had been produced in C3 from 2007 to 2011. As for O3, broccoli, eggplant, and beet had been planted in 2009, tomato in 2010, and pepper in 2011.

All three organic farms were certified by "Florida Organic Growers". Vegetables were grown organically for at least 5 years

TABLE 1. Salmonella enterica Typhimurium (data of strains MAE110 and MAE119 combined) contamination in tomato plants in the two main experiments

\begin{tabular}{lccc}
\hline Experiment, treatment & $\begin{array}{c}\text { Number of internally } \\
\text { contaminated plants/total plants }^{\mathrm{w}}\end{array}$ & $\begin{array}{c}\text { Number of plants with } \\
\text { contaminated fruit/total plants }\end{array}$ & $\begin{array}{c}\text { Number of contaminated } \\
\text { fruit/total fruit }\end{array}$ \\
\hline 1 & & $1 / 42$ & $9 / 270^{\mathrm{x}}$ \\
Inoculated plants in conventional soil & $\ldots$ & $0 / 42$ & $0 / 270$ \\
Inoculated plants in organic soil & $\ldots$ & $0 / 42$ & $0 / 270$ \\
Control plants in organic or conventional soil ${ }^{\mathrm{y}}$ & $\ldots$ & $2 / 42$ & $7 / 250^{\mathrm{z}}$ \\
2 & & $0 / 42$ & $0 / 250$ \\
Inoculated plants in conventional soil & $5 / 42$ & $0 / 42$ & $0 / 250$ \\
Inoculated plants in organic soil & $3 / 42$ & $0 / 42$ & \\
Control plants in organic or conventional soil & & & \\
\hline
\end{tabular}

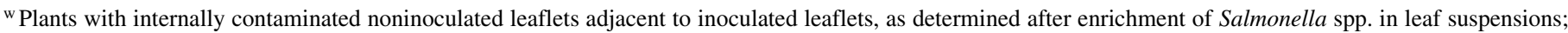
fruit contamination was high enough so that enrichment was not needed.

${ }^{x}$ Nine of nine fruit on one plant.

${ }^{y}$ Equal numbers of organic and conventional soils.

${ }^{\mathrm{z}}$ Five of six fruit on one plant and two of seven fruit on the other plant. 
and composted chicken manure was applied 4 months before harvest. At the conventional farms, crops were grown with typical fertilizer, fungicide, insecticide, and herbicide application schedules.

Two subsamples (500 g) of the collected soil samples were sent to the Analytical Research Laboratory of the Soil and Water Science Department, University of Florida, for analysis of various soil characteristics (http://soilslab.ifas.ufl.edu/). The $\mathrm{pH}$ values and inorganic nitrogen $\left(\mathrm{NH}_{4}{ }^{+}\right.$and $\left.\mathrm{NO}_{3}{ }^{-}\right)$levels of soil samples were detected by the Environmental Protection Agency methods 150.1, 353.2, and 350.1, respectively. Plant-available phosphorus $(\mathrm{P})$, potassium $(\mathrm{K})$, calcium $(\mathrm{Ca})$, and magnesium $(\mathrm{Mg})$ were measured by the Mehlich 3 inductively coupled plasma method (48). Percentage of organic matter in soil samples was analyzed by the Walkley Black method (48).

Leaf inoculation of tomato plants with $S$. enterica Typhimurium. In the first phase of the main experiment, inoculation was carried out by dipping three leaflets on each of two branches per plant into $15 \mathrm{ml}$ of a Salmonella sp. suspension $\left(10^{9} \mathrm{CFU} / \mathrm{ml}\right)$ with $0.025 \%$ (vol/vol) Silwet L-77 (Sigma-Aldrich, St. Louis) for $30 \mathrm{~s}$ (24). Control plants were inoculated with the same amount of SDW with $0.025 \%$ ( vol/vol) Silwet L-77. Tomato plants were inoculated in weeks 5 and 10 in experiment 1 and in weeks 5, 8, 9 , and 10 in experiment 2 .

In experiment 3, three leaflets on each of four branches per plant were dipped into a Salmonella sp. suspension at $10^{9} \mathrm{CFU} / \mathrm{ml}$ with $0.025 \%$ (vol/vol) Silwet L-77 for $30 \mathrm{~s}$. In total, 16 other tomato plants (4 in each soil sample) were inoculated with SDW plus $0.025 \%$ (vol/vol) Silwet L-77. Tomato plants were inoculated 8 weeks after sowing the seed.

Leaf sampling and testing procedure. In the first phase of the main experiment, inoculated and noninoculated leaflets were sampled 14 days after inoculation in experiment 1 and $3 \mathrm{~h}$ and 1 , $3,5,7,14,21$, and 30 days after each inoculation in experiment 2 . At each sampling time, two inoculated leaflets and one noninoculated adjacent leaflet were removed from one randomly selected plant of each treatment in each block. One 12-mm leaf disc was taken with a sterile cork borer from the middle of each inoculated leaflet and dipped in 70\% alcohol for $20 \mathrm{~s}$ and then in $0.6 \%$ sodium hypochlorite for $10 \mathrm{~s}$ to eliminate surface populations of bacteria (24). Each leaflet was sampled only once. Thereafter, leaf discs were rinsed three times by SDW and ground in $1 \mathrm{ml}$ of SDW, the extract was diluted 10-fold in phosphatebuffered saline, and $0.1-\mathrm{ml}$ aliquots of the appropriate dilutions were spread over LB plates (kanamycin at $50 \mu \mathrm{g} / \mathrm{ml}$ ). Adjacent noninoculated leaves were ground and enriched in LB broth (kanamycin at $50 \mu \mathrm{g} / \mathrm{ml}$ ) at $37^{\circ} \mathrm{C}$ for $24 \mathrm{~h}$. Numbers of S. enterica Typhimurium colonies on each petri plate were determined by counting green fluorescent CFU using a UV lamp (UVGL-25; Entela Inc., Grand Rapids, MI). All plates were checked under UV light to exclude the possibility of counting colonies that were not the GFP-marked Salmonella strain. Very few unidentified bacterial colonies were found on the LB agar with kanamycin; these did not show green fluorescence under UV light.

In experiment 3 , one inoculated leaflet per plant was sampled $1,3,5,7,14,21$, and 30 days after inoculation from the four plants of each treatment. One 12-mm leaf disc was taken from inoculated leaflets, surface disinfected, ground in $1 \mathrm{ml}$ of SDW, and plated on LB plates (kanamycin at $50 \mu \mathrm{g} / \mathrm{ml}$ ) after preparing a 10 -fold dilution series. The number of Salmonella colonies was counted as mentioned above. The same numbers of leaflets were tested for control plants.

Tomato leaflets were sampled 2 weeks before the first inoculation and 2 weeks after the last inoculation of Salmonella spp. for endophytic bacterial community analysis. Collected leaflets were stored at $-80^{\circ} \mathrm{C}$ for further analysis later. In the first phase of experiment 2, four leaflets were removed from one randomly selected plant of each treatment in three randomly selected blocks. In experiment 3, four leaflets were removed from three randomly selected plants of each treatment before and after inoculation.

Microscopic observations. In experiment 2, three inoculated leaflets were sampled 1 day after the second inoculation from each of the eight plants inoculated with Salmonella spp. and from eight control plants. Five days later, three noninoculated adjacent leaflets and one stem from each of the eight plants were collected for fluorescent microscopic analysis, as described previously (24). GFP-labeled Salmonella cells in the tissue sections (obtained by cryo-microtome sectioning) were observed under a confocal laser-scanning microscope (Olympus IX81-DSU; Olympus, Japan). In all, 40 tissue sections were examined per leaflet sample, resulting in $40 \times 3 \times 8=960$ sections for inoculated leaflets and 960 sections for adjacent noninoculated leaflets. Thirty sections per stem sample were examined, amounting to $30 \times 8=240 \mathrm{sec}-$ tions. The tissue sections were scanned for fluorescent bacteria under light with an excitation wavelength of $488 \mathrm{~nm}$ and a BA505-525 emission filter (GFP). Time-lapse microscopy of a single field was employed.

DNA extraction, polymerase chain reaction, and denaturing gradient gel electrophoresis. To investigate a possible relationship between internal colonization of S. enterica Typhimurium and endophytic bacterial communities, the Shannon-Wiener diversity index and the species richness of natural endophytic bacteria were determined for tomato plants grown in conventional and organic soils, as described before (36). In brief, leaflets of each sampled plant were surface disinfected by dipping it in $70 \%$ alcohol for $20 \mathrm{~s}$ and $0.6 \%$ sodium hypochlorite for $10 \mathrm{~s}$. Total DNA was extracted from $0.1 \mathrm{~g}$ of surface-disinfected plant tissues using a PowerPlant DNA Isolation Kit (MO BIO Laboratories Inc., Carlsbad, CA) (37). The purified DNA was eluted in $100 \mu \mathrm{l}$ of elution buffer and stored at $-80^{\circ} \mathrm{C}$. These DNA samples (48 in total) were first subjected to $16 \mathrm{~S}$ rDNA polymerase chain reaction (PCR) using primers 799F (16) and1492R (40). The PCR products were electrophoresed on a $1 \%$ agarose gel, and the bacteriumspecific DNA band of the expected size (735 bp) was purified using the Wizard SV gel and PCR clean-up system (Promega Corp., Madison, WI). A second PCR using the purified first PCR product was conducted with primers R1378 (33) and U968 (36); the latter contained a strong 50-GC-clamp required for denaturing gradient gel electrophoresis (DGGE) analysis. DGGE was performed by loading $40 \mu \mathrm{l}$ of second PCR products to the $6 \%$ (wt/vol) polyacrylamide gradient gel containing a linear denaturing gradient of $45-65 \%$ of urea and formamide (47). The gels were run for $16 \mathrm{~h}$ at $60^{\circ} \mathrm{C}$ and $65 \mathrm{~V}$. After electrophoresis, the gels were stained for $30 \mathrm{~min}$ with SYBR Gold nucleic acid gel stain (Life Technologies, Inc., Carlsbad, CA) and bands were visualized by Molecular Imager Gel Doc XR System (Bio-Rad Laboratories, Inc., Hercules, CA).

Fruit sampling and testing procedure. In the main experiment, tomato fruit were sampled for detection of Salmonella spp. contamination, as described before (24). In brief, ripe (fully red in color) tomato fruit were harvested and surface disinfected by sinking them in $70 \%$ alcohol for $2 \mathrm{~min}$, then vertically cut into halves and placed directly with cut side down for 1 min on LB agar plates containing kanamycin at $50 \mu \mathrm{g} / \mathrm{ml}$. The plates were incubated at $37^{\circ} \mathrm{C}$ for $24 \mathrm{~h}$. Salmonella Typhimurium colonies on each petri plate were determined by counting green fluorescent CFU using a UV lamp.

Seed extraction and detection. Tomato pulp was scooped out of each fruit into a plastic container (810 fruit in experiment 1 and 750 fruit in experiment 2). After removing the pulp, the seed were immersed in $1 \mathrm{M} \mathrm{HCl}$ for $30 \mathrm{~min}$ and then $0.1 \%$ tri-sodium phosphate solution for $30 \mathrm{~min}$. Surface-disinfected seed collected in drying bags were placed into dryers $\left(25^{\circ} \mathrm{C}\right)$ for $4 \mathrm{~h}$. To assess the seed contamination rate in experiment 1 , different numbers of seed $(5,10,20$, and 25) from contaminated fruit were ground and incubated in LB broth (kanamycin at $50 \mu \mathrm{g} / \mathrm{ml}$ ) at $37^{\circ} \mathrm{C}$ for $24 \mathrm{~h}$. 
Salmonella colonies were detected on LB agar plates (kanamycin at $50 \mu \mathrm{g} / \mathrm{ml}$ ) under UV light. This test was repeated three times. In experiment 2, all seed extracted from contaminated fruit (257 seeds) and 250 seeds extracted from noncontaminated fruit were plated onto carbon-rich agar plates (55) and placed in a growth chamber at $28^{\circ} \mathrm{C}$ to assess the seed germination rate and $\mathrm{Sal}$ monella spp. contamination rate. Bacterial colonies from the contaminated seed were streaked on LB plates (kanamycin at $50 \mu \mathrm{g} / \mathrm{ml}$ ) and their identity was confirmed under UV light.

Plant dry weight measurements. After harvesting all tomato fruit at the end of phase one in experiment 2, aboveground dry weights of tomato plants were measured, as described previously (24).

Second-generation plant tissue sampling and detection. To investigate seed transmission of Salmonella spp. in experiment 1, 61 seeds from contaminated fruit and 74 seeds from noninoculated control fruit were planted in potting mix; seedlings were transplanted again into potting mix and grown to maturity. Fruit were checked for Salmonella spp. contamination as described above. In experiment 2, 100 seeds extracted from contaminated fruit, including internally contaminated ones that had sprouted on germination plates, and 30 seeds from healthy fruit were planted in conventional soil (same as C1). Salmonella contamination of 390 leaves and 800 fruit in the second generation was checked by enrichment and plating (leaves) or imprinting (fruit halves), as mentioned above.

Statistical analysis. The number of colonies per plate was converted to $\mathrm{CFU} / \mathrm{ml}$ or $\mathrm{CFU} / \mathrm{g}$ (fresh weight) and log-transformed to obtain normal distributions for statistical analysis. The soil management and morphotype effects on the internal persistence of S. enterica Typhimurium in tomato leaves at the inoculation site was evaluated by fitting log-transformed data (separately for each treatment and replication) to the exponential decay model with asymptote $\mathrm{Ct}=\mathrm{A}+(\mathrm{M}-\mathrm{A}) \mathrm{e}^{-\mathrm{Rt}}+\mathrm{Et}(24)$, where $\mathrm{C}=$ $S$. enterica Typhimurium concentration $(\log [\mathrm{CFU} / \mathrm{g}]), \mathrm{t}=$ time (day), $\mathrm{A}=$ asymptote $(\log [\mathrm{CFU} / \mathrm{g}]), \mathrm{M}=$ initial bacterial concentration $(6.4 \log [\mathrm{CFU} / \mathrm{g}]), \mathrm{R}=$ decline rate $\left(\mathrm{day}^{-1}\right)$, and $\mathrm{E}=$ error term. Estimated values of the parameters were obtained for each individual soil and morphotype tested. Estimated rate parameters were subjected to analysis of variance (ANOVA), including the interaction term (morphotype-soil management). Because there was no significant interaction (see Results), main effects of soil management type on Salmonella spp. survival in inoculated leaves were evaluated by multivariate analysis of variance (MANOVA).

Frequencies of plants with Salmonella-positive noninoculated leaflets, plants with Salmonella-positive fruit, and Salmonellapositive fruit out of total fruit were subjected to $\chi^{2}$ tests and Q' tests (43) to check for significant interactions between Salmonella morphotype and soil management type. Main effects of soil management type on proportions of plants and fruit with Salmonella spp. were determined by the Q' test. The $\chi^{2}$ and $z$ tests were conducted to compare the germination rates of seed extracted from contaminated and noncontaminated fruit. The DGGE banding patterns were analyzed using Gelcompar II software (version 1.61; Applied Maths, Woluwe, Belgium) for gel comparison. Each gel contained four marker lanes as standards, and background corrections were performed before identification of bands with $5 \%$ significance threshold. Correspondence of bands between different samples was performed with $1 \%$ dynamic range settings. To determine the soil management effect on endophytic bacterial community composition, the Shannon-Wiener diversity index, based on the number and relative intensity of the DGGE bands, and species richness, based on number of bands, were calculated (57) and compared by ANOVA and $t$ tests. The aboveground dry weights of tomato plants grown in conventional and organic soils with or without Salmonella spp. inoculation were compared by a paired $t$ test.
A paired $t$ test was also used to assess the difference in percentage of organic matter in conventional versus organic soils. Pearson's correlation coefficients were calculated to evaluate the relationships between levels of each nutrient concentration, organic matter content, bacterial richness and diversity, and the decline rate (R) of Salmonella spp. in inoculated leaves.

ANOVA, MANOVA, and $t$ tests were performed using SAS (release 9.2; SAS Institute Inc., Cary, NC). The $\chi^{2}$ and Q' tests were carried out in Microsoft Excel.

\section{RESULTS}

Interaction tests. There were no significant interaction effects between Salmonella morphotype and soil management type on decline rates of Salmonella Typhimurium in inoculated leaflets as determined by ANOVA $(P=0.23)$. Similarly, there were no significant interaction effects between Salmonella morphotype and soil management type on numbers of plants with positive noninoculated leaflets $(P=1.00)$, numbers of plants with positive fruit $(P=0.56)$, and number of positive fruit $(P=0.61)$ using the $\chi^{2}$ test. The $P$ values for the Q' tests determining these interactions were $0.72,0.67$, and 0.64 , respectively. The absence of significant interactions justified describing only the main effects of soil management type in this article.

Survival of $S$. enterica Typhimurium in tomato plants. In the first phase of experiment 1, the population of Salmonella spp. in tomato leaves on plants grown in conventional soils $(3.81 \pm 0.17$ $\log [\mathrm{CFU} / \mathrm{g}])$ was significantly higher than that on plants grown in organic soils $(3.27 \pm 0.24 \log [\mathrm{CFU} / \mathrm{g}]) 2$ weeks after inoculation $(P=0.0117)$. In experiment 2 , levels of Salmonella spp. inside tomato leaves decreased significantly faster in the plants grown in organic soil (O1) than in those grown in conventional soil $(\mathrm{C} 1)$ (Fig. 1A). There were no differences in the decline in Salmonella populations among the blocks. The effect of soil management type on the internal persistence of Salmonella spp. in tomato leaves was confirmed in experiment 3 (Fig. 1B).

Based on the data of the main and extra experiments, Salmonella populations inside surface-disinfested leaves of tomato plants grown in both conventional and organic soils decreased after inoculation (Fig. 1). The exponential decay model used to describe survival of Salmonella spp. in each sample had a mean square error of 0.0157 in experiment 2 and 0.1480 in experiment 3 and a coefficient of variation $\left(R^{2}\right)$ of 0.987 in experiment 2 and 0.939 in experiment 3. With respect to estimates of $\mathrm{R}$ (decline rate) and A (asymptote), the ability of Salmonella spp. to persist in plant tissues was significantly reduced when plants were grown in organically managed soils, with an overall Wilk's Lambda significance value of 0.016 in experiment 2 and 0.0228 in experiment 3 (Table 2). The $\mathrm{R}$ values of "organic" plants were significantly higher than those of "conventional" plants $(P=$ 0.016 in experiment $2, P=0.0325$ in experiment 3 ), while the A values were lower for organic samples $(P=0.012$ in experiment $2, P=0.0176$ in experiment 3$)$. Thus, $S$. enterica Typhimurium persisted longer inside leaves of tomato plants grown in conventional soils than in leaves of plants grown in organic soils.

Salmonella spp. entered into all dip-inoculated tomato leaflets 1 day after inoculation, as determined by both dilution plating and microscopic observations under a confocal laser microscope. No Salmonella sp. was detected in the noninoculated control plants. In addition, Salmonella CFU were detected after enrichment of suspensions of adjacent noninoculated leaflets of eight tomato plants at 5 days post first inoculation in experiment 2 (five plants grown in conventional soils and three in organic soils) (Table 1). Under the confocal laser microscope, GFP-marked Salmonella cells were only observed in noninoculated adjacent leaves and stems of the five inoculated plants grown in conventional soils (not in organic soils) 5 days post second inoculation; however, the 
frequency of the detection was not very high (1\% positive for leaf cross-sections and $2 \%$ positive for stem cross-sections).

Soil sample properties and correlation to internal persistence of $S$. enterica Typhimurium in tomato leaves. The $\mathrm{pH}$ values of all the soil samples were similar and ranged from 6.4 to 7.3. The chemical characteristics of soil samples are shown in Table 3. As expected, the percentage of organic matter in organic soils was significantly higher than that of conventional soils $(P=$ 0.0325). Levels of $\mathrm{NH}_{4}{ }^{+}, \mathrm{NO}_{3}{ }^{-}, \mathrm{P}$, and $\mathrm{K}$ of soil samples did not affect susceptibility of tomato to Salmonella spp. proliferation and survival. However, there was a strong positive correlation between the soil levels of $\mathrm{Ca}$ or $\mathrm{Mg}$ and the decline rate of Salmonella spp. in plant tissues under organic and conventional production (Table 3).

Endophytic bacterial communities in tomato plants grown in conventional and organic soils. The Shannon diversity index and species richness of endophytic bacterial communities were both higher in the organic plants than those in conventional plants before and after Salmonella spp. inoculation $(P<0.05)$. The endophytic bacterial diversity was significantly reduced after inoculation $(P=0.023)$, whereas the richness was not significantly changed $(P=0.463)$. There was no interaction between soil management types and Salmonella spp. inoculation. There was a positive correlation between the Salmonella spp. decline rate and the Shannon diversity index $(r=0.851 ; P=0.0321)$, whereas the decline rate was not correlated to the species richness ( $r=0.629 ; P=0.180)$ (Table 3$)$.

Fruit and seed contamination of tomato plants grown in conventional soil. In experiment 1,810 fruit were collected from 126 tomato plants (540 from inoculated plants and 270 from control plants). All nine tomato fruit on one plant were positive for GFP-marked Salmonella spp., and that one plant was grown in conventional soil (C1). No symptoms were observed on or in the Salmonella-positive fruit. A Salmonella sp. was not recovered from 5 or 10 seeds per batch but was recovered from sets of $\geq 20$ seeds obtained from contaminated fruit, indicating that the contamination rate was $\approx 5 \%$. None of $\approx 800$ fruit from secondgeneration plants were contaminated with Salmonella spp.

In experiment 2, a total of 750 tomato fruit collected from the 126 tomato plants (500 from inoculated plants and 250 from control plants) were tested for the presence of Salmonella spp. in tomato pulp. Two of seven harvested tomato fruit from one plant and five of six harvested tomato fruit from another plant were Salmonella spp. positive. Both of these two plants were grown in conventional soil (C1) and also tested positive for Salmonella spp. in adjacent noninoculated leaflets (Table 1). No Salmonella sp. was detected in any of the 250 organically produced fruit tested. The distributions of the bacterial cells in the conventional pulp are shown in Figure 2, where B presents the Salmonella colonies recovered from the corresponding contaminated fruit shown in A on LB plates with kanamycin at $50 \mu \mathrm{g} / \mathrm{ml}$. In total, 257 seeds were extracted from the seven contaminated fruit in experiment 2. Salmonella spp. were detected on 12 surface-sterilized seeds $(4.7 \%)$ of these fruit when germinated on agar (Fig. 2C and D), which supported the previous observation that the contamination rate of seed in infested fruit was $\approx 5 \%$. No Salmonella sp. was detected in the 250 seeds extracted from noncontaminated fruit. Of 257 seeds extracted from contaminated fruit, 25 did not germinate. In contrast, only 9 of 250 seeds extracted from noncontaminated fruit did not germinate. The germination rate of seed from contaminated fruit $(90.3 \%)$ was significantly lower (z test: $P=0.00596 ; \chi^{2}$ test: $P=0.00582$ ) than that of seed from noncontaminated fruit $(96.4 \%)$. In the second phase of experiment 2, no Salmonella spp. contamination was detected by dilution plating after enrichment of suspensions from $\approx 390$ leaves and 800 fruit. However, one seedling of the 12 internally contaminated seeds died after germination; none of the control seedlings died.

TABLE 2. Parameter estimates for the exponential decline of Salmonella enterica Typhimurium concentrations in tomato leaves over a 30-day period ${ }^{\mathrm{y}}$

\begin{tabular}{lcc}
\hline Experiment, soil $^{\mathrm{z}}$ & $\mathrm{A}(\log [\mathrm{CFU} / \mathrm{g}])$ & $\mathrm{R}\left(\mathrm{day}^{-1}\right)$ \\
\hline 2 & & \\
Conventional soil & $3.826 \pm 0.129 \mathrm{a}$ & $0.039 \pm 0.023 \mathrm{a}$ \\
$\quad$ Organic soil & $2.071 \pm 1.715 \mathrm{~b}$ & $0.168 \pm 0.059 \mathrm{~b}$ \\
3 & & \\
Conventional soil & $3.877 \pm 0.229 \mathrm{a}$ & $0.044 \pm 0.043 \mathrm{a}$ \\
Organic soil & $0.027 \pm 1.012 \mathrm{~b}$ & $0.219 \pm 0.059 \mathrm{~b}$ \\
\hline
\end{tabular}

y $\mathrm{A}=$ asymptote and $\mathrm{R}=$ decline rate. Letters indicate significant differences $(P=0.05)$ between treatments within each of the experiments.

${ }^{\mathrm{z}}$ Experiment number and soil management type.

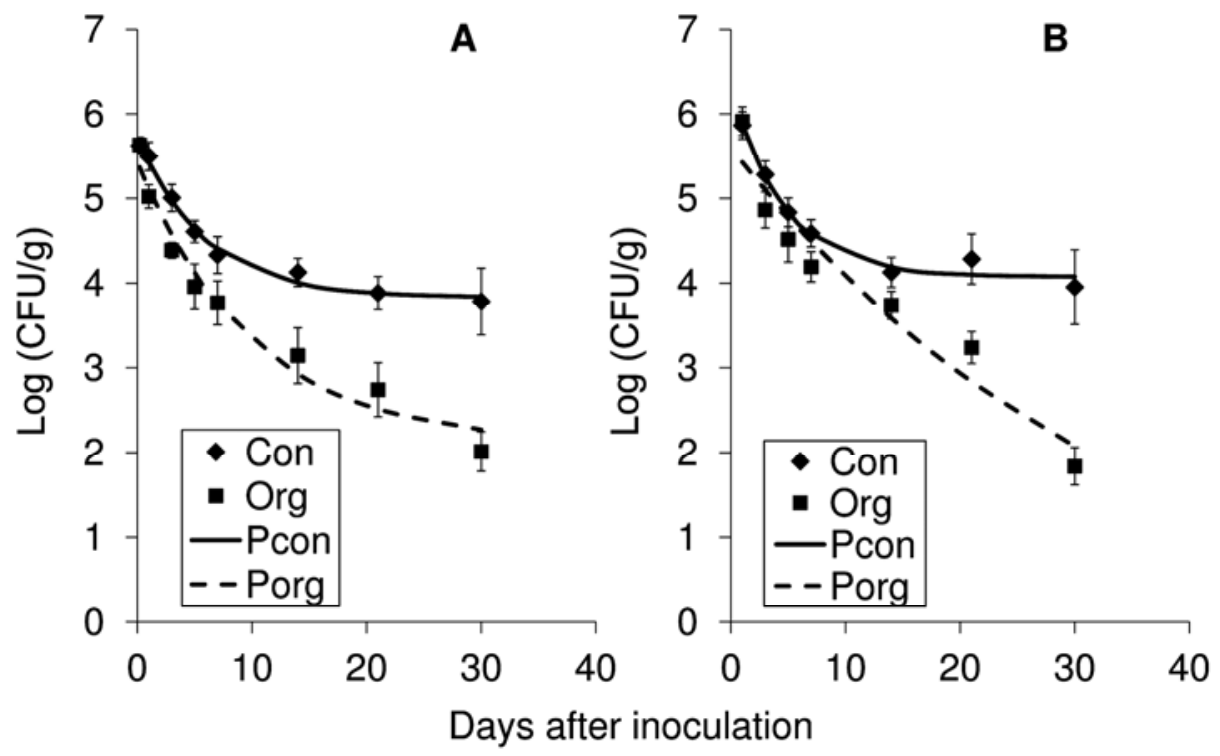

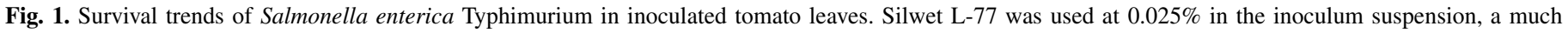

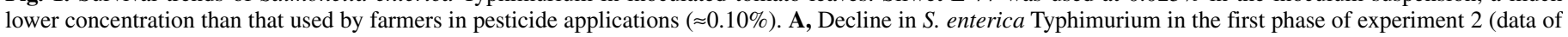

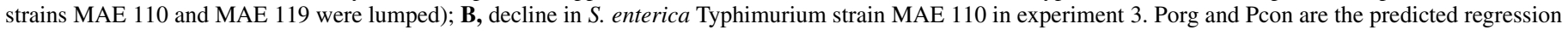

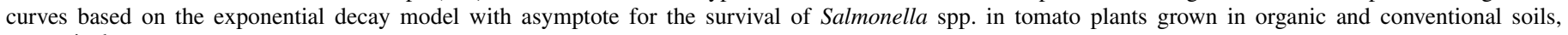
respectively. 
Thus, Salmonella spp. can contaminate fruit and seed through leaf inoculation but the chance of seed transmission to the next generation is very low when seedlings are planted in separate pots and watered from below.

Aboveground dry weight of tomato plants grown in conventional and organic soils. Our previous study showed that the inoculation with Salmonella strains significantly reduced the aboveground dry weights of tomato plants (24). However, the aboveground dry weights of tomato plants grown in conventional or organic soils in phase one of experiment 2 were not significantly different either with $(P=0.1454)$ or without $(P=0.1468)$ Salmonella spp. inoculation, which indicated that soil management did not affect the biomass production of tomato plants.

\section{DISCUSSION}

Our study conclusively shows, for the first time, that $S$. enterica Typhimurium can reach not only tomato fruit but also seed via leaf inoculation, although the chance is low $(\approx 0.25 \%$ of the conventionally produced seed when leaves are inoculated with a suspension of $10^{9} \mathrm{CFU} / \mathrm{ml}$ plus $0.025 \%$ Silwet, a much lower concentration than that used by growers for pesticide applications). In addition, internal colonization of Salmonella spp. in tomato leaves was affected by soil management type. Within 30 days after inoculation of tomato leaves, endophytic populations of S. enterica Typhimurium declined at least 100-fold more in the tissues of plants grown under organic than in those under conventional conditions. The decline rates were $\approx 4.6$ times higher in the plants grown in organic soil than those in conventional soil. Moreover, Salmonella cells were not observed under the confocal laser microscope in noninoculated leaves sampled from inoculated plants grown in organically managed soil but were observed in the conducting tissues of noninoculated leaves of inoculated plants in conventional soil. Confocal laser micrographs were shown in a recent article (24) but without indication of the soil used for plant growth. Here, we report that Salmonella cells were found in phloem cells in the stem of conventionally grown plants but not in those grown organically.

Internalization of Salmonella spp. in plants has been observed frequently $(24,36,38)$ but enhanced colonization and survival in plants grown in conventionally managed soil compared with organically managed soil has not been published. One possible cause for the accelerated decline of Salmonella spp. in organically grown plants is that increased levels of $\mathrm{Ca}$ and $\mathrm{Mg}$ in organic soils resulted in greater resistance of tomato leaves to Salmonella spp. colonization. Ca is known to result in sturdier cell walls and better membrane function (29), which could increase plant resistance under disease stress (17). $\mathrm{Mg}$ fertilization has a positive influence on the proliferation of oligotrophic bacteria, which could increase the diversity and richness of the bacterial community (62). Another hypothesis is that the diversity of the endophytic bacterial community, which was higher in plants grown in organic soils than those in conventional soils, led to reduced internal colonization of Salmonella spp. In a previous report, natural endophytic bacterial species richness was negatively correlated to the internal colonization of Salmonella spp. (36). Several other reports showed a negative correlation between endophytic bacterial diversity and infection by a plant pathogen $(1,28)$. A negative correlation between endophytic bacteria and plant or enteric pathogen colonization could be related to competition by a more diverse community or induced systemic resistance (20). Higher microbial diversity and activity in organic soils may have stimulated systemic plant resistance to Salmonella spp. more in tomato grown in organic conditions compared with tomato grown in conventional conditions (3). Salicylic acid levels in organic tomato
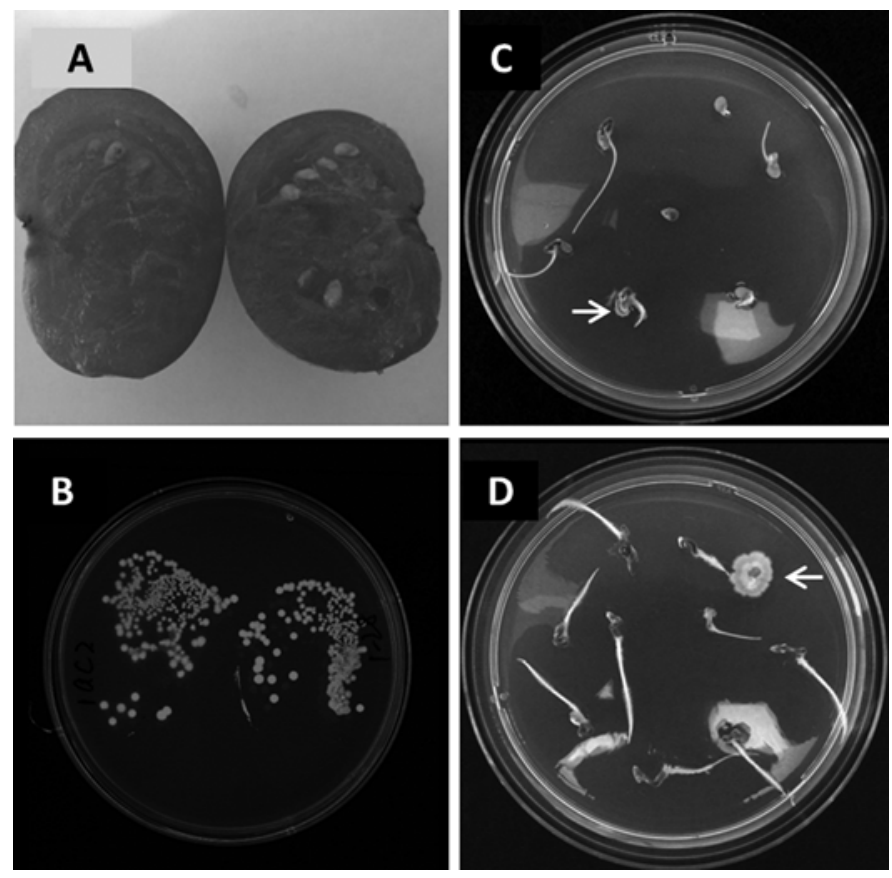

Fig. 2. Tomato fruit and seed contamination of Salmonella enterica Typhimurium. A, Contaminated cut fruit; B, Salmonella colonies recovered from the fruit shown in A on Luria-Bertani plates with kanamycin; C and D, internal contamination of tomato seed when germinating on carbon-rich agar with $\approx 1,000$ ppm C (55).

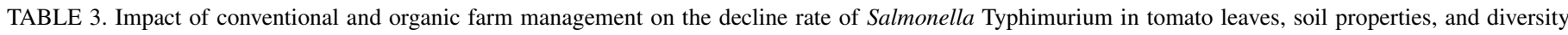

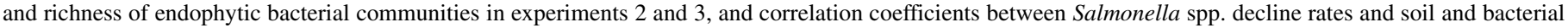
community properties $^{\mathrm{v}}$

\begin{tabular}{|c|c|c|c|c|c|c|c|c|c|c|}
\hline Soil $^{\mathrm{w}}$ & Rate $^{\mathrm{x}}$ & $\begin{array}{c}\mathrm{NH}_{3} \\
(\mathrm{mg} / \mathrm{kg})\end{array}$ & $\begin{array}{c}\mathrm{NOx} \\
(\mathrm{mg} / \mathrm{kg})\end{array}$ & $\begin{array}{c}\mathrm{P} \\
(\mathrm{mg} / \mathrm{kg})\end{array}$ & $\begin{array}{c}\mathrm{K} \\
(\mathrm{mg} / \mathrm{kg})\end{array}$ & $\begin{array}{c}\mathrm{Ca} \\
(\mathrm{mg} / \mathrm{kg})\end{array}$ & $\begin{array}{c}\mathrm{Mg} \\
(\mathrm{mg} / \mathrm{kg})\end{array}$ & OM (\%) & Diversity ${ }^{\mathrm{y}}$ & Richness $^{\mathrm{z}}$ \\
\hline $\mathrm{C} 1$ & 0.039 & 0.45 & 10.1 & 85 & 32 & 841 & 39 & 1.33 & 2.55 & 0.85 \\
\hline $\mathrm{C} 2$ & 0.043 & 0.43 & 3.9 & 174.2 & 96.2 & 304.4 & 21.5 & 1.19 & 2.46 & 0.80 \\
\hline C3 & 0.045 & 0.68 & 6.1 & 150.9 & 38.1 & 1,215 & 62.9 & 1.98 & 2.54 & 0.81 \\
\hline $\mathrm{O} 1$ & 0.168 & 0.64 & 3.9 & 668 & 81 & 2,628 & 98 & 2.33 & 2.89 & 0.92 \\
\hline $\mathrm{O} 2$ & 0.114 & 1.42 & 3.4 & 114.4 & 11.6 & 371.9 & 33.8 & 1.79 & 2.62 & 0.89 \\
\hline $\mathrm{O} 3$ & 0.307 & 0.73 & 3.53 & 141.3 & 74.3 & 2,972 & 95.2 & 2.57 & 2.84 & 0.88 \\
\hline Correlation & $\ldots$ & 0.215 & -0.528 & 0.233 & 0.292 & 0.832 & 0.759 & 0.844 & 0.851 & 0.629 \\
\hline
\end{tabular}

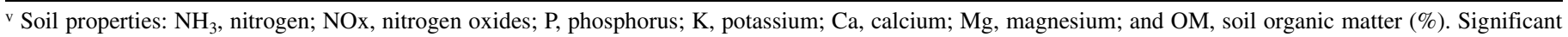
correlation coefficients $(\alpha<0.05)$ between levels of a nutrient, organic matter content or bacterial diversity and the decline rate of Salmonella spp. are shown in bold.

${ }^{\mathrm{w}} \mathrm{C} 1$ to $\mathrm{C} 3$, soils collected from different conventional farms; O1 to O3, soils collected from different organic farms.

${ }^{x}$ Rate of Salmonella spp. decline (log [CFU/g]/day) was measured by fitting observed data (as in Figure 1) to an exponential decline model with asymptote.

${ }^{y}$ Diversity of endophytic bacterial community before inoculation.

${ }^{\mathrm{z}}$ Richness of endophytic bacterial community before inoculation. 
fruit were significantly higher than those in conventionally cultivated ones (52). Further studies will be conducted to evaluate the relationships between bacterial diversity, systemic acquired resistance, induced systemic resistance, and the internal colonization of tomato plants by Salmonella spp.

In these studies, Silwet L-77, a surfactant which can increase the internal colonization of Salmonella spp. in tomato plants (24), was added to the inoculum suspension at $0.025 \%$ (vol/vol). Silwet L-77and other surfactants are commonly used at a concentration of $0.10 \%$ ( $\mathrm{vol} / \mathrm{vol}$ ) in conventional farming systems when liquid fertilizers or pesticides are applied. The observed increase of the ingress of Salmonella spp. in tomato leaves when applied with surfactants (24) may enhance the risk of Salmonella spp. contamination of tomato fruit grown in conventional farms. Further studies will be conducted to investigate the mechanisms of the increased Salmonella spp. internalization by surfactants.

In our experiments, Salmonella spp. survived on tomato plants grown in both conventional and organic soils. As reported by us previously, more Salmonella CFU were detected on the inoculated leaf surface than inside the leaf tissues (24). Thus, the total Salmonella spp. population on and in leaves may not be significantly different between the two soil management types. However, the internal population decreases more quickly inside leaf tissues of plants grown in organic soils. The internal contamination of Salmonella spp. in tomato would be more important for fresh produce food safety due to the inability to disinfect interior compared with surface contamination during the post-harvest stage of the food supply chain.

Some previous studies reported a rather low probability of internal leaf and fruit contamination with Salmonella spp. (24,25). Therefore, high cell densities and a surfactant were used to increase the probability of Salmonella spp. internalization in order to study its movement into noninoculated leaves and fruit. Further studies with larger sample numbers $(>1,000$ tomato plants) and lower inoculum concentrations (such as $10^{6} \mathrm{CFU} / \mathrm{ml}$ ) are needed to evaluate the soil management effect on internal contamination of Salmonella spp. inside plant leaves, fruit, and seed in the field. In addition, only one tomato cultivar and one Salmonella serovar were used, whereas the interactions between tomato and Salmonella spp. may vary based on differences in plant cultivars and bacterial serovars or strains $(5,7,49)$. Moreover, the effect of soil management type may also be relative to the soil physical properties and how well the farmers manage the fields. Further studies would need to be conducted to assess these effects. Finally, the number of contaminated seed available for the second generation limited the chance to detect seed transmission. Salmonella spp. were not detected in plants (61 in experiment 1 and 100 plants in experiment 2) grown from the seed extracted from contaminated fruit in the main experiment. Further experiments with large sample sizes (probably $>1,000$ ) of internally contaminated seed are needed to assess the risks of seed transmission for Salmonella spp. contamination in real tomato production systems.

\section{ACKNOWLEDGMENTS}

This research was funded by IFAS of the University of Florida. We thank M. Teplitski, J. B. Jones, and J. A. Bartz for insightful comments during the preparation of the manuscript.

\section{LITERATURE CITED}

1. Abbasi P. A., Al-Dahmani J., Sahin F., Hoitink H. A. J., and Miller, S. A. 2002. Effect of compost amendments on disease severity and yield of tomato in conventional and organic production systems. Plant Dis.. 86:156-161

2. Alali, W. Q., Thakur, S., Berghaus, R. D., Martin, M. P., and Gebreyes, W. A. 2010. Prevalence and distribution of Salmonella in organic and conventional broiler poultry farms. Foodborne Pathog. Dis. 7:1363-1371.

3. Araujol, W. L., Marcon, J., Maccheroni, W., van Elsas, J. D., van Vuurde,
J. W. L., and Azevedo, J. L. 2002. Diversity of endophytic bacterial populations and their interaction with Xylella fastidiosa in citrus plants. Appl. Environ. Microbiol. 68:4906-4914.

4. Aruscavage, D., Lee, K., Miller, S., and LeJeune, J. T. 2006. Interactions affecting the proliferation and control of human pathogens on edible plants. J. Food Sci. 71:R89-R99.

5. Barak, J. D., Kramer, L. C., and Hao, L. Y. 2011. Colonization of tomato plants by Salmonella enterica is cultivar dependent, and type 1 trichomes are preferred colonization sites. Appl. Environ. Microbiol. 77:498-504.

6. Barak, J. D., and Liang, A. S. 2008. Role of soil, crop debris, and a plant pathogen in Salmonella enterica contamination of tomato plants. Plos One 3:e1657.

7. Barak, J. D., Liang A., and Narm, K. E. 2008. Differential attachment to and subsequent contamination of agricultural crops by Salmonella enterica. Appl. Environ. Microbiol. 74:5568-5570.

8. Barak, J. D., Whitehand, L. C., and Charkowski, A. O. 2002. Differences in attachment of Salmonella enterica serovars and Escherichia coli O157:H7 to alfalfa sprouts. Appl. Environ. Microbiol. 68:4758-4763.

9. Brandl, M. T. 2006. Fitness of human enteric pathogens on plants and implications for food safety. Annu. Rev. Phytopathol. 44:367-392.

10. Brandl, M. T., and Amundson, R. 2008. Leaf age as a risk factor in contamination of lettuce with Escherichia coli O157:H7 and Salmonella enterica. Appl. Environ. Microbiol. 74:2298-2306.

11. Brandl, M. T., Rosenthal, B. M. Haxo, A. F., and Berk S. G. 2005. Enhanced survival of Salmonella enterica in vesicles released by a soilborne Tetrahymena species. Appl. Environ. Microbiol. 71:1562-1569.

12. Campbell, J. V., Mohle-Boetani, J., Reporter, R., Abbott, S., Farrar, J., Brandl, M., Mandrell, R., and Werner S. B. 2001. An outbreak of Salmonella serotype Thompson associated with fresh cilantro. J. Infect. Dis. 183:984-987.

13. CDC. 2005. Outbreaks of Salmonella infections associated with eating Roma tomatoes-United States and Canada, 2004. Can. Commun. Dis. Rep. 31:225-228.

14. CDC. 2007. Multistate outbreaks of Salmonella infections associated with raw tomatoes eaten in restaurants-United States, 2005-2006. Morb. Mortal. Wkly. Rep. 56:909-911.

15. Cevallos-Cevallos, J. M., Danyluk, M. D., Gu, G., Vallad, G. E., and van Bruggen, A. H. C. 2011. Dispersal of Salmonella Typhimurium by rain splash onto tomato plants. J. Food Prot. 75:472-479.

16. Chelius, M. K., and Triplett, E. W. 2001. The diversity of archaea and bacteria in association with the roots of Zea mays L. Microb. Ecol. 41:252-263.

17. Datnoff, W., Elmer, H., and Huber, D. M., eds. 2007. Mineral Nutrition and Plant Disease. The American Phytopathological Society, St. Paul, $\mathrm{MN}$.

18. Franz, E., and van Bruggen, A. H. C. 2008. Ecology of E. coli O157:H7 and Salmonella enterica in the primary vegetable production chain. Crit. Rev. Microbiol. 34:143-161.

19. Gallegos-Robles, M. A., Morales-Loredo, A., Alvarez-Ojeda, G., Vega, P. A., Chew, M. Y., Velarde, S., and Fratamico, P. 2008. Identification of Salmonella serotypes isolated from cantaloupe and chile pepper production systems in Mexico by PCR-restriction fragment length polymorphism. J. Food Prot. 71:2217-2222.

20. Granér, G., Persson, P., Meijer, J., and Alström, S. 2003. A study on microbial diversity in different cultivars of Brassica napus in relation to its wilt pathogen, Verticillium longisporum. FEMS Microbiol. Lett. 224:269-276.

21. Gravel, V., Blok, W., Hallmann, E., Carmona-Torres, C., Wang, H. Y., Van de Peppel, A., Golec, M., Dorais, A. F. C., Van Meeterens, U., Heuvelink, E., Rembialkowska, E., and van Bruggen, A. H. C. 2010. Differences in N uptake and fruit quality between organically and conventionally grown greenhouse tomatoes. Agron. Sustain. Dev. 30:797-806.

22. Gray, E. J., and Smith, D. L. 2005. Intracellular and extracellular PGPR: commonalities and distinctions in the plant-bacterium signaling processes. Soil Biol. Biochem. 37:395-412.

23. Greene, S. K., Daly E. R., Talbot, E. A., Demma, L. J., Holzbauer, S., Patel, N. J., Hill, T. A., Walderhaug, M. O., Hoekstra, R. M., Lynch, M. F., and Painter, J. A. 2008. Recurrent multistate outbreak of Salmonella Newport associated with tomatoes from contaminated fields, 2005. Epidemiol. Infect. 136:157-65.

24. Gu, G., Hu, J., Cevallos-Cevallos, J. M., Richardson, S. M., Bartz, J. A., and van Bruggen, A. H. C. 2011. Internal colonization of Salmonella enterica serovar Typhimurium in tomato plants. Plos One 6:e27340.

25. Guo, X., Chen, J., Brackett, R. E., and Beuchat, L. R. 2001. Survival of Salmonellae on and in tomato plants from the time of inoculation at flowering and early stages of fruit development through fruit ripening. Appl. Environ. Microbiol. 67:4760-4764.

26. Guo, X., Chen J., Brackett R. E., and Beuchat, L. R. 2002. Survival of Salmonella on tomatoes stored at high relative humidity, in soil, and on tomatoes in contact with soil. J. Food Prot. 65:274-279. 
27. Gupta, S. K., Nalluswami, K., Snider, C., Perch, M., Balasegaram, M., Burmeister, D., Lockett, J., Sandt, C., Hoekstra, R. M., and Montgomery, S. 2007. Outbreak of Salmonella Braenderup infections associated with Roma tomatoes, northeastern United States, 2004: A useful method for subtyping exposures in field investigations. Epidemiol. Infect. 135:11651173.

28. Hakizimana, J. D., Gryzenhout, M., Coutinho, T. A., and van den Berg, N. 2011. Endophytic diversity in Persea americana (avocado) trees and their ability to display biocontrol activity against Phytophthora cinnamomi. Pages 1-10 in: Proc. VII World Avocado Congress 2011. Cairns, Australia.

29. Haydar, M., Moledina, K., Ooraikul, B., and Hadziyev, D. 1980. Effect of calcium and magnesium on cell-wall and starch of dehydrated potato granules. J. Agric. Food Chem. 28:383-391.

30. He, M., Ma, W., Tian, G., Blok, W., Khodzaeva, A., Zelenev, V. V., Semenov, A. M., and van Bruggen, A. H. C. 2010. Daily changes of infections by Pythium ultimum after a nutrient impulse in organic versus conventional soils. Phytopathology 100:593-600.

31. He, M., Tian, G., Semenov, A. M., and van Bruggen, A. H. C. 2011. Short-term fluctuations of sugar-beet damping-off by Pythium ultimum in relation to changes in bacterial communities after organic amendments to two soils. Phytopathology 102:413-420.

32. Heaton, J. C., and Jones, K. 2008. Microbial contamination of fruit and vegetables and the behaviour of enteropathogens in the phyllosphere: A review. Appl. Environ. Microbiol. 104:613-626.

33. Heuer, H., and Smalla, K. 1997. Application of denaturing gradient gel electrophoresis (DGGE) and temperature gradient gel electrophoresis (TGGE) for studying soil microbial communities. Pages 353-373 in: Modern Soil Microbiology. J. D. van Elsas, E. M. H. Wellington, and J. T. Trevors, eds. Marcel Dekker, Inc., New York.

34. Hiddink, G. A., van Bruggen, A. H. C, Termorshuizen, A. J., Raaijmakers, J. M., and Semenov, A. V. 2005. Effect of organic management of soils on suppressiveness to Gaeumannomyces graminis var. tritici and its antagonist, Pseudomonas fluorescens. Eur. J. Plant Pathol. 113:417-435.

35. Islam, M., Morgan, J., Doyle, M. P., and Phatak, S. C. 2004. Fate of Salmonella enterica serovar Typhimurium on carrots and radishes grown in fields treated with contaminated manure composts or irrigation water. Appl. Environ. Microbiol. 70:2497-2502.

36. Klerks, M. M., Franz, E., van Gent-Pelzer, M., Zijlstra, C., and van Bruggen, A. H. C. 2007. Differential interaction of Salmonella enterica serovars with lettuce cultivars and plant-microbe factors influencing the colonization efficiency. ISME J. 1:620-631.

37. Klerks, M. M., van Bruggen, A. H. C., Zijlstra, C., and Donnikov, M. 2006. Comparison of methods of extracting Salmonella enterica serovar Enteritidis DNA from environmental substrates and quantification of organisms by using a general internal procedural control. Appl. Environ. Microbiol. 72:3879-3886.

38. Klerks, M. M., van Gent-Pelzer, M., Franz, E., Zijlstra, C., and van Bruggen, A. H. C. 2007. Physiological and molecular responses of Lactuca sativa to colonization by Salmonella enterica serovar Dublin. Appl. Environ. Microbiol. 73:4905-4914.

39. Kroupitski, Y., Pinto, R., Brandl, M. T., Belausov, E., and Sela, S. 2009. Interactions of Salmonella enterica with lettuce leaves. J. Appl. Microbiol. 106:1876-1885.

40. Lane, D. J. 1991. 16S/23S rRNA sequencing. Pages 115-175 in: Nucleic Acid Techniques in Bacterial Systematics. E. Stackebrandt and M. Goodfellow, eds. John Wiley \& Sons, Chichester, UK.

41. Mahon, B. E., Ponka, A., Hall, W. N., Komatsu, K., Dietrich, S. E., Siitonen, A., Cage, G., Hayes, P. S., Lambert-Fair, M. A., Bean, N. H., Griffin, P. M., and Slutsker, L. 1997. An international outbreak of Salmonella infections caused by alfalfa sprouts grown from contaminated seeds. J. Infect. Dis. 175:876-882.

42. Mendes, R., Kruijt, M., de Bruijn, I., Dekkers, E., van der Voort, M., Schneider, J. H., Piceno, Y. M., DeSantis, T. Z., Andersen, G. L., Bakker, P. A., and Raaijmakers, J. M. 2011. Deciphering the rhizosphere microbiome for disease-suppressive bacteria. Science 332:1097-1100

43. Michael, G. A. 2007. A significance test of interaction in $2 \times \mathrm{K}$ designs with proportions. Tutorials Quant. Methods Psychol. 3:1-7.

44. Mohle-Boetani, J. C., Reporter, R., Werner, S. B., Abbott, S., Farrar, J., Waterman, S. J., and Vugia, D. J. 1999. An outbreak of Salmonella serogroup Saphra due to cantaloupes from Mexico. J. Infect. Dis. 180:1361-1364.
45. Mukherjee, A., Speh, D., Dyck, E., and Diez-Gonzalez, F. 2004. Preharvest evaluation of coliforms, Escherichia coli, Salmonella, and Escherichia coli $\mathrm{O} 157: \mathrm{H} 7$ in organic and conventional produce grown by Minnesota farmers. J. Food Prot. 67:894-900.

46. Mukherjee, A., Speh, D., Jones, A. T., Buesing, K. M., and DiezGonzalez, F. 2006. Longitudinal microbiological survey of fresh produce grown by farmers in the upper Midwest. J. Food Prot. 69:1928-1936.

47. Muyzer, G., de Waal, E. C., and Uitterlinden, A. G. 1993. Profiling of complex microbial populations by denaturing gradient gel electrophoresis analysis of polymerase chain reaction-amplified genes coding for $16 \mathrm{~S}$ rRNA. Appl. Environ. Microbiol. 59:695-700.

48. Mylavarapu, R. S. 2012. UF/IFAS Extension Soil Testing Laboratory (ESTL) Analytical Procedures and Training Manual. Univ. Fla. IFAS Ext. Circ. 1248. http://edis.ifas.ufl.edu/pdffiles/SS/SS31200.pdf

49. Noel, J. T., Arrach, N., Alagely, A., McClelland, M., and Teplitski, M. 2010. Specific responses of Salmonella enterica to tomato varieties and fruit ripeness identified by in vivo expression technology. Plos One 5:e12406.

50. Oliveira, M., Usall, J., Vinas, I., Anguera, M., Gatius, F., and Abadias, M. 2010. Microbiological quality of fresh lettuce from organic and conventional production. Food Microbiol. 27:679-684.

51. O’Mahony, M., Cowden, J., Smyth, B., Lynch, D., Hall, M., Rowe, M., Teare, E. L., Tettmar, R. E., Rampling, A. M., Coles, M., and Gilbert, R. J., Kingcott, E., and Bartlett, C. L. R. 1990. An outbreak of Salmonella Saintpaul infection associated with beansprouts. Epidemiol. Infect. 104:229-235.

52. Rossi, F., Godani, F., Bertuzzi, T., Trevisan, M., Ferrari, F., and Gatti, S. 2008. Health-promoting substances and heavy metal content in tomatoes grown with different farming techniques. Eur. J. Nutr. 47:266-272.

53. Semenov, A. M., Kupriyanov, A. A., and van Bruggen, A. H. C. 2010. Transfer of enteric pathogens to successive habitats as part of microbial cycles. Microbiol. Ecol. 60:239-249.

54. Semenov, A. V., van Overbeek, L., Termorshuizen, A. J., and van Bruggen, A. H. C. 2011. Influence of aerobic and anaerobic conditions on survival of Escherichia coli O157:H7 and Salmonella enterica serovar Typhimurium in Luria-Bertani broth, farm-yard manure and slurry. J. Environ. Manage. 92:780-787.

55. Senechkin, I. V., Speksnijder, A. G., Semenov, A. M., van Bruggen, A. H. C., and van Overbeek, L. S. 2010. Isolation and partial characterization of bacterial strains on low organic carbon medium from soils fertilized with different organic amendments. Microbiol. Ecol. 60:829-839.

56. van Diepeningen, A. D., de Vos, O. J., Korthals, G. W., and van Bruggen, A. H. C. 2006. Effects of organic versus conventional management on chemical and biological parameters in agricultural soils. Appl. Soil Ecol. 31:120-135.

57. van Diepeningen, A. D., de Vos, O. J., Zelenev, V. V., Semenov, A. M., and van Bruggen, A. H. C. 2005. DGGE fragments oscillate with or counter to fluctuations in cultivable bacteria along wheat roots. Microbiol. Ecol. 50:506-517.

58. van Elsas, J. D., Chiurazzi, M., Mallon, C. A., Elhottova, D., Kristufek, V., and Salles, J. F. 2012. Microbial diversity determines the invasion of soil by a bacterial pathogen. Proc. Natl. Acad. Sci. USA 109:1159-1164.

59. van Overbeek, L. S., Franz, E., Semenov, A.V., de Vos, O. J., and van Bruggen, A. H. C. 2010. The effect of the native bacterial community structure on the predictability of E. coli O157:H7 survival in manureamended soil. Lett. Appl. Microbiol. 50:425-430.

60. Wetzel, K., Lee, J., Lee, C. S., and Binkley, M. 2010. Comparison of microbial diversity of edible flowers and basil grown with organic versus conventional methods. Can. J. Microbiol. 56:943-951.

61. Winthrop, K. L., Palumbo, M. S., Farrar, J. A., Mohle-Boetani, J. C., Abbott, S., Beatty, M. E., Inami, G., and Werner, S. B. 2003. Alfalfa sprouts and Salmonella Kottbus infection: a multistate outbreak following inadequate seed disinfection with heat and chlorine. J. Food Prot. 66:1317.

62. Wyszkowska, J., and Wyszkowski, M. 2002. Effect of cadmium and magnesium on microbiological activity in soil. Pol. J. Environ. Stud. 11:585-591.

63. Zogaj, X., Nimtz, M., Rohde, M., Bokranz, W., and Rőmling, U. 2001. The multicellular morphotypes of Salmonella typhimurium and Escherichia coli produce cellulose as the second component of the extracellular matrix. Mol. Microbiol. 39:1452-1463. 